\title{
Isolation and Characterization of Ethanol, Sugar and Thermo Tolerant Yeast Isolates in Ethiopia
}

\author{
Taye Negera \\ Oromia Agricultural Research Institute \\ Holeta Bee Research Center \\ Holeta, Ethiopia
}

\begin{abstract}
The yeasts were isolated from (Psidium guajava), grapefruit (Citrus paradise), avocado (Persea americana), papaya (Carica papaya) and gishita (Annona senegalensis pers.). All the yeast isolates were first tested for carbohydrate fermentation using Durham tube fermentation method in yeast extract peptone dextrose broth. Four isolates which were relatively high fermentative in Durham tube fermentation method were selected for testing of the isolates for ethanol, sugar and thermo tolerance. Further, the optimum conditions for isolation and characterization of yeast isolates were determined. The investigation revealed that the optimum conditions are $37^{\circ} \mathrm{C}$ temperature, $30 \%$ sugar concentration, $15 \%$ ethanol concentration and $\mathrm{pH}$ 5. The aim of the study was to isolate and characterize ethanol, sugar and thermo tolerant yeast to optimize maximal ethanol production from coffee husk.
\end{abstract}

Keywords: Fruits, optical density, S. cerevisiae, Thermo tolerant and Yeast isolates

\section{INTRODUCTION}

The use of bio-fuel to substitute fossil fuels has immense benefits for non-oil producing countries. Sugar, starch and lignocelluloses are carbohydrate-rich raw materials suitable for ethanol production. Bio-fuel includes bio-ethanol, bio-butanol (where sourced from starchy crops) and biodiesel from oil crops such as Jatropha curcas, castor crop and palm tree which are used for ethanol production with worldwide acceptance essentially to overcome problems associated with exploitation and depletion of fossil fuels and environmental pollution. Thus, ethanol production can be effected using easily available substrates such as lignocelluloses and (or) hemicelluloses and micro-organisms which could convert them into ethanol could be very useful [1].

The ability of yeast to produce ethanol depends on many factors such as strains, growth factors and optimum environmental conditions [2]. Tolerance of yeast to its substrate (osmo-tolerance), fermentation product (ethanol- tolerance) and temperature (thermo-tolerance) has great potential to be used in industrial scale fermentation. Isolation and characterization of ethanol, sugar and thermo tolerant yeast from fruits could promote higher yield of ethanol at higher temperature than commercial Saccharomyces cereviciae like baker yeast. Therefore the main objectives of this research work to isolate and characterize yeast from different fruits, evaluate the yeast isolate for ethanol, sugar and heat tolerance for bio-ethanol production under different environmental condition.

\section{MeTHODS}

\subsection{Sampling Site and Sample Collection}

Two hundred seventy six different sample of fruits belongs to five species, guava (53) (Psidium guajava), grapefruit (56) (Citrus paradise), avocado (57) (Persea americana), papaya(54) (Carica papaya) and gishita (56) (Annona senegalensis pers.) were collected from Southwestern Ethiopia, Jimma ,Sheka, Kefa, Gurage and Bench-Maji Zone and Addis Ababa fruit market (Atikilt Tera) using sterile plastic bags and brought to the Mycology Laboratory, Department of Microbial, Cellular and Molecular Biology, Addis Ababa University and the samples were kept at $4{ }^{\circ} \mathrm{C}$ for farther study.

\subsection{Isolation and Screening of Ethanol, Sugar and Thermo Tolerant Yeasts}

The yeasts were isolated from five species; guava (Psidium guajava), grapefruit (Citrus paradise), avocado (Persea Americana), papaya (Carica papaya) and gishita (Annona senegalensis pers.) 
samples after dilution followed by plating aliquots of appropriate dilution of samples on yeast extract peptone dextrose agar (YPDA). One $\mathrm{ml}$ of each of the sample was transferred to nine $\mathrm{ml}$ of sterile distilled water to be successively diluted to $10^{-1}$ up to $10^{-6}$. Aliquots of $0.1 \mathrm{ml}$ from final dilutions $\left(10^{-3}\right.$ and $10^{-4}$ ) were spread onto YPDA [3]. The YPDA medium contains g/l of yeast extract 10 , peptone 20, dextrose (glucose) 20, and agar 20. It supplemented with $0.1 \mathrm{mg} / \mathrm{ml}$ streptomycin sulphate antibiotics to inhibit bacterial growth [4]. The plates were incubated at $37^{\circ} \mathrm{C}$ about 24 and $48 \mathrm{hrs}$. Morphologically distinguished colonies were selected under a dissection microscope. Yeast isolates were purified by sub culturing on YPD medium by streaking. The Pure culture was kept on YPD slant agar and stored at $4^{\circ} \mathrm{C}$ for further study.

\subsection{Morphological Characterization}

The yeast isolate from grapefruit were designated by AAUD, the yeast isolate from guava were designated by AAUZ. The yeast isolates from avocado were designated by AAUAV. The yeast isolates from papaya were designated by AAUP $\left(\mathrm{AAUP}_{1}, \mathrm{AAUP}_{2}\right.$ and $\left.\mathrm{AAUP}{ }_{3}\right)$ and the yeast isolates from gishita (Annona senegalensis pers.) were designated by AAUG ( $\mathrm{AAUG}_{1}, \mathrm{AAUG}_{2}$ and $\left.\mathrm{AAUG}_{3}\right)$. The vegetative cells morphology determined by growing both in liquid and on solid culture media YPD [5and6]. The microscopic traits (size, shape and methods of vegetative reproduction).were identified by examining under microscope.

\subsubsection{Growth $n$ Solid nd Liquid Medium}

The morphology of yeast isolates were determined by growing on solid and in liquid media; that was composed of YPD and agar (solidifying agent) at $37^{\circ} \mathrm{C}$ about 3 days[7]. The traits recorded were colonies colors, and textures, ascospore and pseudo mycelium formation.

\subsubsection{Ascospore Formation}

The selected yeast isolates were examined for ascospore formation using presporulation and sporulation [8]. The presporulation medium composed $20 \mathrm{~g}$ of glucose, $2 \mathrm{~g}$ of ammonium sulfate $\left(\left(\mathrm{NH}_{4}\right)_{2} \mathrm{SO}_{4}\right), 2 \mathrm{~g}$ of potassium dihydrogen phosphate $\left(\mathrm{KH}_{2} \mathrm{PO}_{4}\right)$ and $5 \mathrm{~g}$ of yeast extract in $1000 \mathrm{ml}$ of distilled water and the medium was kept in sterile state for 7 days. The medium was inoculated with a loopful young culture of $48 \mathrm{hrs}$ old and incubated at $25^{\circ} \mathrm{C}$, on shaker for 3 days. The sporulation medium consisted of $1 \mathrm{~g}$ of glucose, $8.2 \mathrm{~g}$ of potassium acetate, $2.5 \mathrm{~g}$ of yeast extract and $1.86 \mathrm{~g}$ of magnesium sulfate heptahydrate $\left(\mathrm{MgSO}_{4} .7 \mathrm{H}_{2} \mathrm{O}\right)$ in $1000 \mathrm{ml}$ of distilled water. The medium was inoculated with a drop of yeasts from the presporulation medium and incubated at $25^{\circ} \mathrm{C}$. The culture was examined microscopically for ascospores production at weakly intervals for 3 weeks. Ascospore formation was detected by staining the heat-fixed preparation with carbol-fuchsin [5]. Slides were decolorized with $95 \%$ ethanol containing $1 \%$ concentrated hydrochloric acid. They were slide was rinsed in water and counter stained with $1 \%$ methylene blue to observe the mature ascospores stain red and blue stains of the vegetative cells.

\subsubsection{Pseudo Mycelium Formation}

The formation of pseudo mycelium was investigated by slide culture technique [5]. A Petri dish was containing a U-shaped glass rod supporting glass slide, was sterilized by dry heat at $180^{\circ} \mathrm{C}$ for $2 \mathrm{hrs}$. YPD agar was melted and poured into a second sterile Petri dish. The glass slide was quickly removed from the glass rod dipped into the medium after which it was replaced on the glass rod support. After solidification of the agar on the slide, the isolates were inoculated very lightly in two lines along the slide and a sterile cover slip was placed over part of the lines. Sterile water was poured into the Petri dish to prevent the agar from drying out. The culture was incubated at $25^{\circ} \mathrm{C}$ for 5 days.

\subsection{Testing of Yeast Isolates for Carbohydrate Fermentation Using Durham Tube Method}

Durham tube was used for testing of yeasts for carbohydrate fermentation. Yeast fermentation YP broth was used characterization of the yeast isolates based on fermentation of specific carbohydrates. The carbohydrates used were; glucose, galactose, maltose, sucrose, lactose trehalose, fructose and xylose. Yeast fermentation broth was modification of media developed by Wickerham for the determination carbohydrate to detect the color of the medium and gas formation [9]. Yeast fermentation broth with carbohydrate and Durham tube composed of $4.5 \mathrm{~g}$ of yeast extracts, $7.5 \mathrm{~g}$ of peptone, $80 \mathrm{~g}$ of lactose, $120 \mathrm{~g}$ of raffinose, $60 \mathrm{~g}$ other carbohydrates and $17 \mathrm{~g}$ of bromcresol blue per liter deionized filtered water and final $\mathrm{pH} 7.1 \pm 2$ at $25^{\circ} \mathrm{C}$. 


\subsection{Optimization of Temperature for Ethanol, Sugar and Thermo Tolerant Yeast Isolates Growth}

Fifty $\mathrm{ml}$ of YPD medium was distributed into $125 \mathrm{ml}$ screw cap Erlenmeyer flask and inoculated with actively growing culture [10]. All cultures were incubated at $30{ }^{\circ} \mathrm{C}, 37{ }^{\circ} \mathrm{C}, 40{ }^{\circ} \mathrm{C}$ and $45{ }^{\circ} \mathrm{C}$ for 72 hrs. The initial optical density (OD) of each culture in flasks was read for UV absorbance at $660 \mathrm{~nm}$ using a Pye-Unicam SP6 spectrophotometer. The treatments were replicated three times and the blank was made of YPD medium without yeast inoculation. The OD is directly proportional to the cell mass or growth (one $\mathrm{OD}_{660} \mathrm{~nm}=1.85 \times 10^{7 \mathrm{cell} / \mathrm{ml}}$ ).

\subsection{Optimization of Ethanol Tolerance of the Yeast Isolates}

The medium for the detection of ethanol tolerance of ethanol, sugar and thermo tolerant yeast was modified from [4]. YPD liquid medium was used for the tests. The medium was sterilized at $121{ }^{\circ} \mathrm{C}$ for $15 \mathrm{~min}$ in an autoclave and cooled. One $\mathrm{ml}$ of various concentrations of absolute ethanol was taken from 5 to $25 \%(\mathrm{v} / \mathrm{v})$, and transferred to different flasks $(125 \mathrm{ml})$. Forty $\mathrm{ml}$ of the medium was distributed into each flask and then inoculated with selected isolates. The initial optical density (OD) of each culture in flasks was read for UV absorbance at $660 \mathrm{~nm}$ using a Pye-Unicam SP6 spectrophotometer. The treatments were replicated three times and the blank was made of YPD medium without yeast inoculation. The OD is directly proportional to the cell mass or growth (one $\mathrm{OD}_{660} \mathrm{~nm}=1.85 \times 10^{7 \mathrm{cell} / \mathrm{ml}}$ ). All cultures were incubated at $37^{\circ} \mathrm{C}$ for 3 days. The increase in optical density in a flask was recorded as evidence of growth.

\subsection{Optimizations of Glucose Tolerance of the Yeast Isolates}

Testing of glucose tolerance, YPD broth was prepared containing 10\%, 15\%, 30\%, $45 \%$ and $50 \%$ of different sugar concentrations [11]. The initial optical density (OD) of each culture in flasks was read for UV absorbance at $660 \mathrm{~nm}$ using a Pye-Unicam SP6 spectrophotometer. The treatments were replicated three times and the blank was made of YPD medium without yeast inoculation. The OD is directly proportional to the cell mass or growth (one $\mathrm{OD}_{660} \mathrm{~nm}=1.85 \times 10^{7 \mathrm{cell} / \mathrm{ml}}$ ). All cultures were incubated at $37^{\circ} \mathrm{C}$ for $48 \mathrm{hrs}$. The increase in optical density in a flask was recorded as evidence of growth.

\section{RESUlt AND DisCUSSION}

\subsection{Isolation and Screening of Ethanol, Sugar and Thermo Tolerant Yeasts}

A total of nine yeast isolates were retriered from five different fruit samples collected from Southwestern Ethiopia and Addis Ababa fruits markets, one from guava (Psidium guajava), grapefruit (Citrus paradise) and avocado (Persea americana) and three from papaya (Carica papaya) and gishita (Annona senegalensis pers.). Most colonies were creamy (whitish) oval, convex and dome shaped except one isolate from papaya, which was pink after ten days of fermentation. All yeast isolates were reproduced by budding (Table 1 ).

\subsection{Identification of the Yeast Isolates}

\subsubsection{Morphological and Physiological Characteristics of the Yeast Isolates}

Table 1. Summary of Morphological Features of Yeast Isolates

\begin{tabular}{|l|l|l|l|l|l|}
\hline Character & AAUP & AAUD & AAUG & AAUAV & S.cer.(commercial) \\
\hline Surface & Smooth & Smooth & Smooth & Smooth & Smooth \\
\hline Margin & Slightly crispulate & Crispulate & Crispulate & $\begin{array}{l}\text { Slightly } \\
\text { crispulate }\end{array}$ & Crispulate \\
\hline Color & Cream, white & Cream, white & Cream, white & Cream, white & Cream, white \\
\hline Elevation & Convex & Slightly Convex & Convex & Convex & Convex \\
\hline Cell & $\begin{array}{l}\text { spheroidal,ellipsoidal } \\
\text { Multilaterial } \\
\text { budding }\end{array}$ & $\begin{array}{l}\text { spheroidal, } \\
\text { lipsoidal } \\
\text { ultilaterialbuding }\end{array}$ & $\begin{array}{l}\text { spheroidal, } \\
\text { ellipsoidal } \\
\text { Multilaterial } \\
\text { budding }\end{array}$ & $\begin{array}{l}\text { spheroidal, } \\
\text { ellipsoidal } \\
\text { Multilaterial } \\
\text { budding }\end{array}$ & $\begin{array}{l}\text { spheroidal, ellipsoidal } \\
\text { Multilaterial } \\
\text { budding }\end{array}$ \\
\hline Ascospore & + & + & + & + & + \\
\hline Psedomycelium & + & + & + & + & + \\
\hline
\end{tabular}


All of yeast isolates were observed under compound microscope and cell morphology was observed after 3 days of incubation, at $37^{\circ} \mathrm{C}$, heavy, dry climbing pellicles were formed on the surface of YPD broth medium. The growth was butyrous with white cream color on YPD agar (Table 3). The cell morphology of $\mathrm{AAUP}_{1}, \mathrm{AAUD}, \mathrm{AAUG}_{3}$ and AAUAV isolates was ovoidal to elongate and had single, pairs, or triple budding cells and Pseudo mycelia were also developed. Ascospore formed in ascospore forming media after incubating for 3 weeks at $25^{\circ} \mathrm{C}$. Similar results reported that, filamentous pseudomycelium is characteristic of Saccharomyces cerevisiae, which is dimorphic, existing either in spherical, unicellular yeast like morphology or in a filamentous form [12].

\subsection{Testing of Yeast Isolates for Carbohydrate Fermentation Using Durham Tube Method}

In this study, the yeast isolates showed variation in utilization of eight different sugars. Almost all isolates utilized glucose, galactose, sucrose, maltose, fructose and trehalose. All isolates failed to grow on xylose and lactose. The most vigorous isolates were AAUP ${ }_{1}, \mathrm{AAUD}, \mathrm{AAUAV}$ and $\mathrm{AAUG}_{3}$ growing on several of the test carbohydrates (Table 2). This was similar with results reported [13].

Table 2. Comparison and Selection of Yeast Isolates By Durham Tube Yeast Extract Peptone dextrose (YPD) liquid medium fermentation method

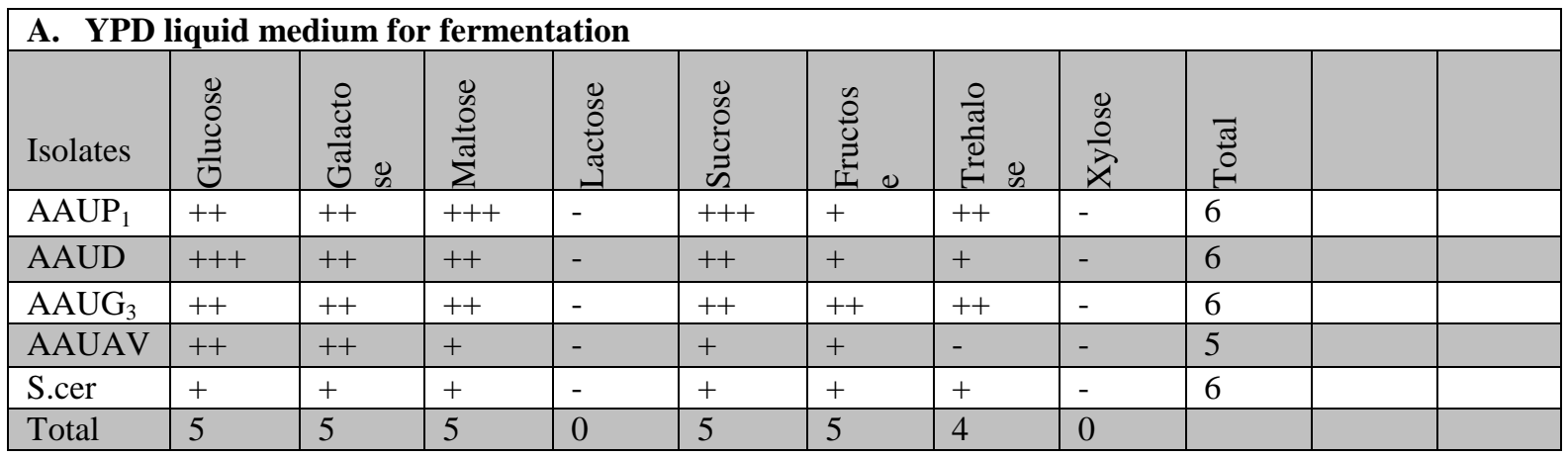

Key: $+=$ fermentative, $++=$ high fermentative, $+++=$ very high fermentative (empty Durham tube)

\subsection{Optimization of Temperature for the Growth of Ethanol, Sugar and Thermo Tolerant Yeast Isolates}

The effect of temperature on the growth of yeast isolates was study under the range of $30-45^{\circ} \mathrm{C}$. The highest cell dry weight was at $37^{\circ} \mathrm{C}$ but for commercial yeast $30^{\circ} \mathrm{C}$ (Figure 2). Accordingly AAUP ${ }_{1}$, $\mathrm{AAUD}, \mathrm{AAUG}_{3}$ and AAUAV were relatively the highest thermo tolerant than the other yeast isolates. The four yeast isolates were resistant to high temperature in the broth media and high fermentative when compared to the other isolates (Figure 2). Four isolates identified as thermo tolerant, they are $\mathrm{AAUP}_{1}, \mathrm{AAUD}, \mathrm{AAUG}_{3}$ and AAUAV. The most thermo tolerant isolates were AAUD tolerant to $45^{\circ} \mathrm{C}$, followed by isolate $\mathrm{AAUG}_{3}$ which was tolerant to $40^{\circ} \mathrm{C}$ temperature in the broth media (Figure 2).

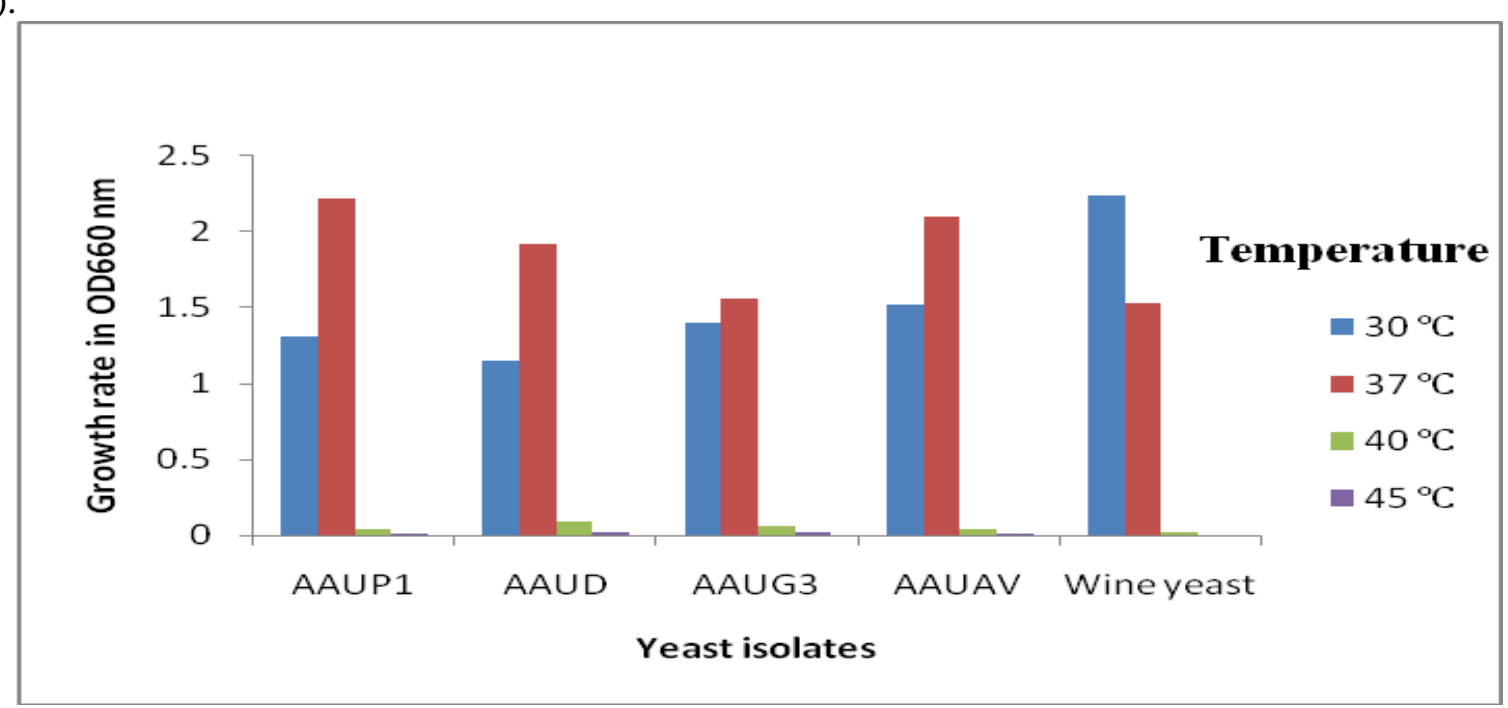

Figure 2. The Effect of Temperature on the Growth of Thermo Tolerant Yeast Isolates Cultivated In Ypd Broth For 3 Days (dry weight in od $660 \mathrm{~nm}$ ) 


\subsection{Ethanol Tolerance of the Yeast Isolates}

Yeast isolates (AAUP $1, \mathrm{AAUD}, \mathrm{AAUG}_{3}$ and AAUAV) were able to grow in $\geq 5 \%(\mathrm{v} / \mathrm{v})$ ethanol concentration (Figure 3). There were slight differences observed in growth rates while increasing the ethanol concentration from 5 to $10 \%(\mathrm{v} / \mathrm{v})$ and 15 to $25 \%(\mathrm{v} / \mathrm{v})$. The most ethanol tolerant yeast isolates $\left(\mathrm{AAUG}_{3}\right.$ ) that was isolated from gishita (Annona senegalensis pers.) with ethanol tolerance to $15 \%(\mathrm{v} / \mathrm{v})$ followed by the yeast isolate (AAUD) from grape with ethanol tolerant of $10 \%(\mathrm{v} / \mathrm{v})$ ethanol in the broth medium (Figure 4). The isolates AAUAV was tolerant to ethanol up to $10 \%$ (v/v). Accordingly, AAUP $1, \mathrm{AAUD}, \mathrm{AAUG}_{3}$ and AAUAV were relatively rapidly fermentative and the highest ethanol tolerant.

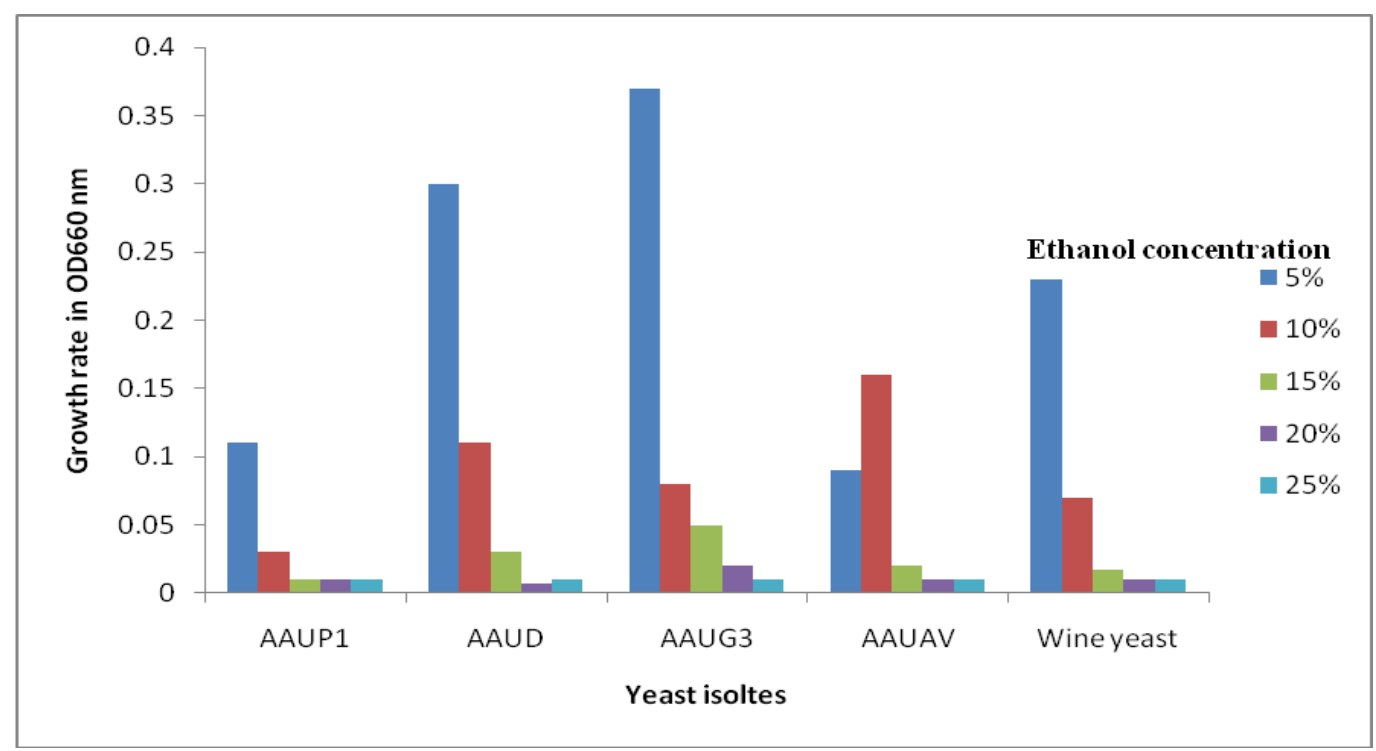

Figure 3. The Growth Response of Yeast Isolates In Relation To Ethanol Concentrations (\%, V/V) In YPD Medium (Dry Weight In $O D_{660} \mathrm{Nm}$ )

\subsection{Sugar Tolerance of The Yeast Isolates}

Sugar tolerance the yeast isolates (AAUP $1, A A U D, A_{1} A_{3}$ and AAUAV) increased in growth at an increasing concentration up to $30 \%$ but decreased slightly at concentration up to 50\% (Figure 5). The most sugar tolerant was AAUAV with sugar tolerance capacity of up to $50 \%$ (v/v) followed by isolates $\mathrm{AAUG}_{3}$ which was tolerant to $45 \%$ (v/v) sugar concentration in the broth media. In general $\mathrm{AAUP}_{1}, \mathrm{AAUD}, \mathrm{AAUG}_{3}$ and AAUAV were the highest sugar tolerant than other yeast isolates (Figure 4). These four yeast isolates were identified as resistant to high sugar concentration in the broth medium.

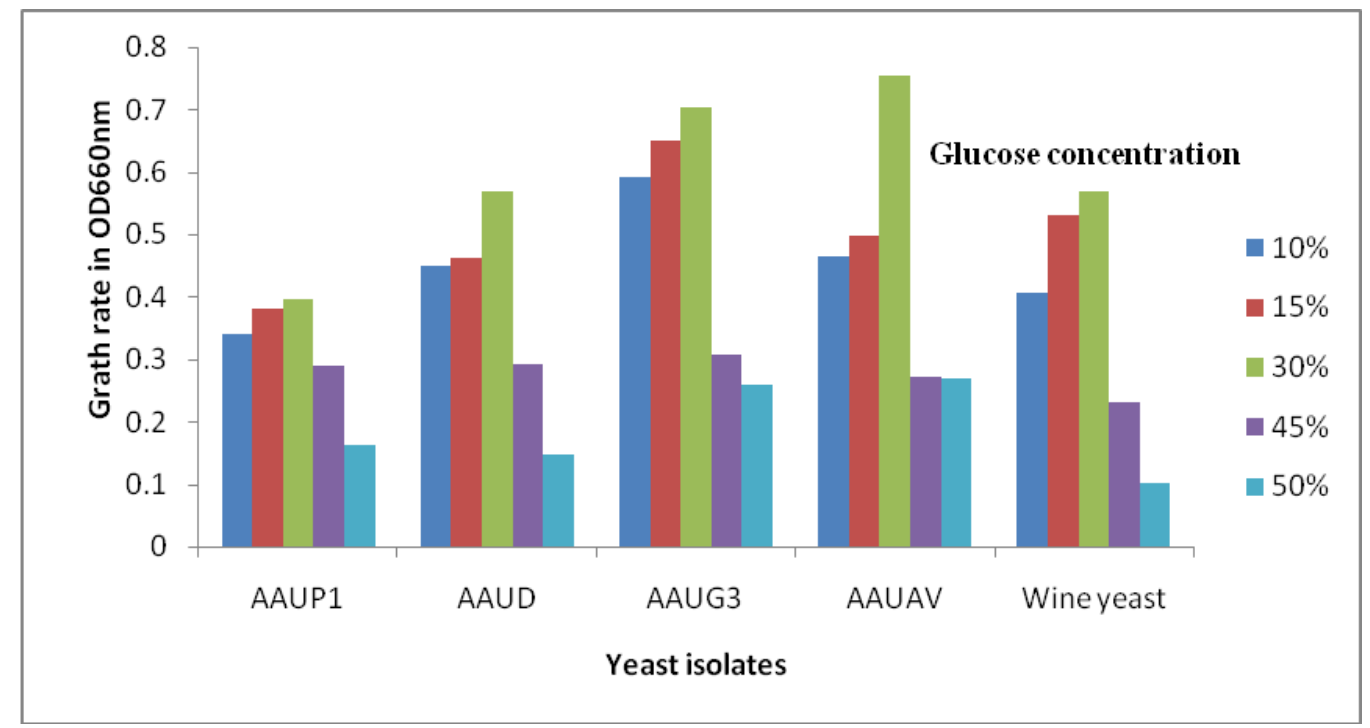

Figure 4. Summary of yeast isolates growth rate response for various glucose concentrations $(\%, w / v)$ in ypd medium (dry weight in ${ }^{\circ} d_{660} \mathrm{~nm}$ ) 


\subsection{Optimization of $\mathrm{Ph}$ for Growth of the Yeast Isolates}

The growth rate of yeast isolates increased along with the $\mathrm{pH}$ level increase to 3.0. The $\mathrm{pH}$ of the medium did not show different effect on growth rate at $\mathrm{pH} 3.0$ to 6.5, beyond which the growth was decreased. At medium pH 7.0 to 8.0, the final dry mass was slightly decreased (Figure 6). The highest dry mass was observed in the medium where the $\mathrm{pH}$ was 5.0 for all yeast isolates (Figure 6).

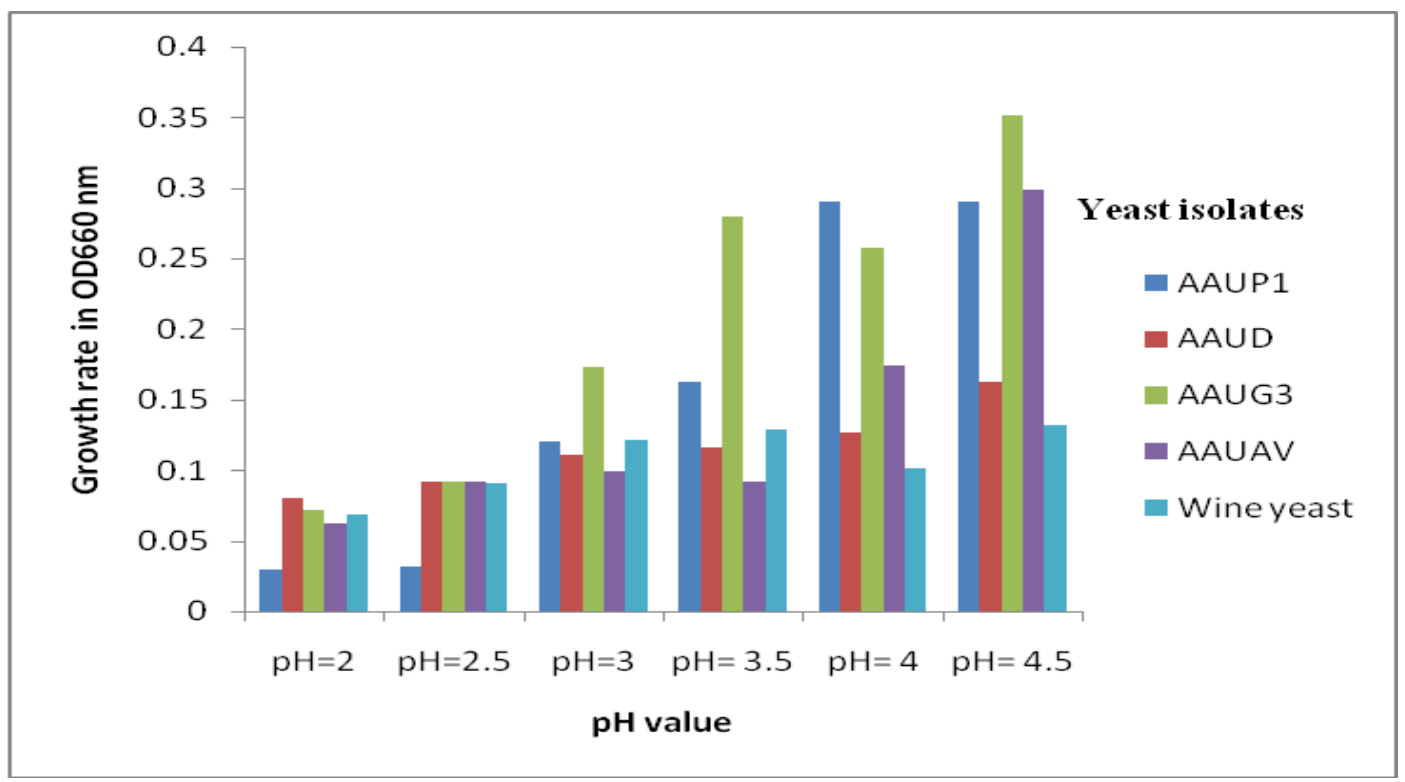

Figure 5.

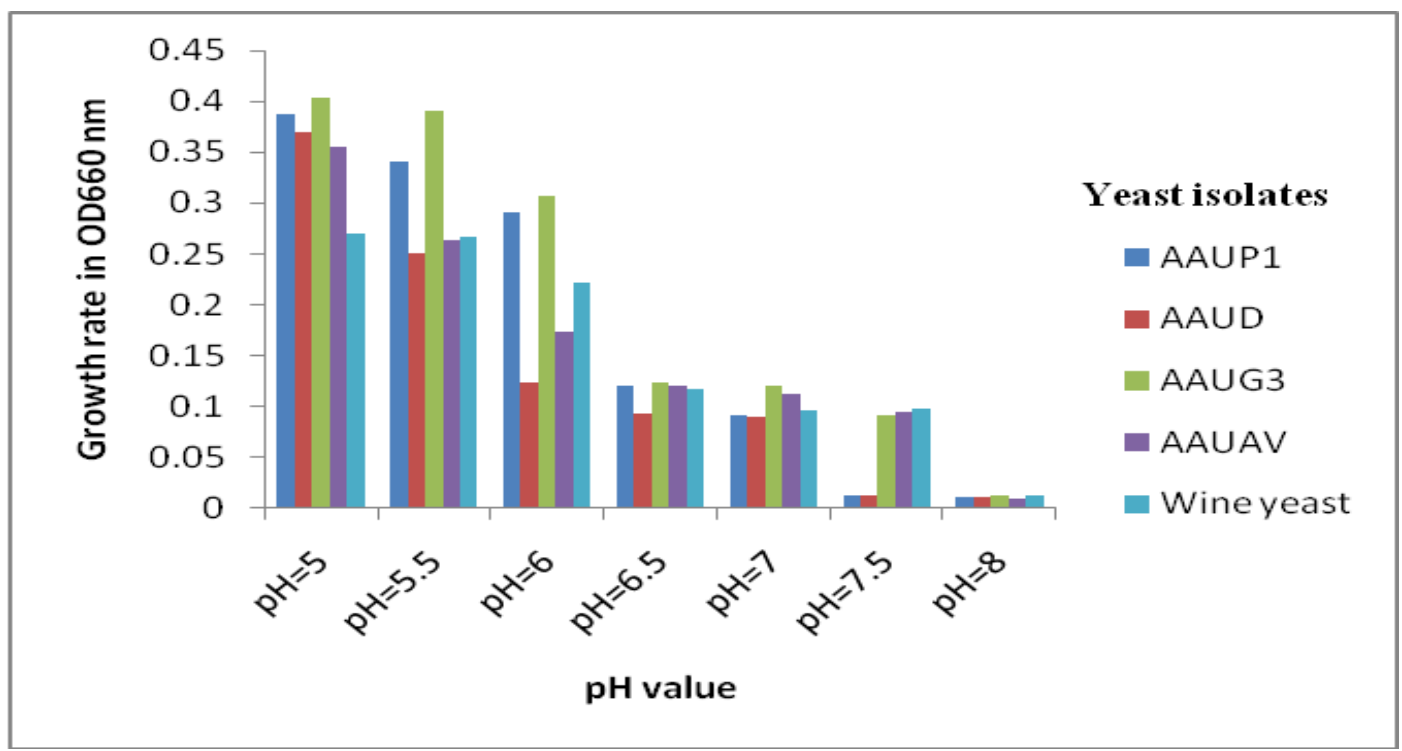

Figure 6. Summary of the effect of $\mathrm{pH}$ on the growth of the yeast isolates (Dry weight in $O D_{660} \mathrm{~nm}$ )

\section{Conclusion}

Based on morphological and physiological characteristics, the four yeast isolates were grouped under the genus saccharomyces which were closely related to $S$. cerevisiae. The yeast isolates, $\mathrm{AAUG}_{3}$ that was isolated from gishita (Annona senegalensis pers.) showed higher ethanol tolerance $(15 \% \mathrm{v} / \mathrm{v})$ than other yeast isolates. The yeast isolate, AAUD that was isolated from grapefruit was more thermo tolerant $\left(45^{\circ} \mathrm{C}\right)$ than the other yeast isolates. Four yeast isolates showed best growth, at $37{ }^{\circ} \mathrm{C}$ and optimum condition for their growth.

\section{ACKNOWLEDGEMENTS}

I am grateful to Addis Ababa University Department of Microbial, Cellular and Molecular Biology for offering me postgraduate study grant and financial assistance. I am also very thankful to Mycology laboratory technicians, Zenebech Aytenew and Negat Mekonen for their unreserved contribution in one way or another for the success of my study. 
My grateful appreciation is extended to Department of Chemistry, for providing me the Laboratory facilities and I am very glad to express my sincere gratitude to Dr. Mesin Redi for his continuous encouraging me to effectively complete my study. I would also like to thank Mis Senayt Dagne for her kindly training me in preparing chemicals and experimental set up for acid hydrolysis and quantification of ethanol production. I thanks to Mr. Ayalew Debebe (Department of Chemistry a $\mathrm{PhD}$ candidate) for his time and effort in assisting with the Fourier Transform Infrared (FTIR) analysis.

\section{REFERENCES}

[1] Mogg, R., Biofuels in Asia: Thailand relaunches gasohol for automotive use. Refocus 5: 44-47 (2004).

[2] Khongsay, N.; Laopaiboon, L. and Laopaiboon, P., Growth and Batch fermentation of Saccharomyces cerevisiae on sweet sorghum stem juice under normal and very high gravity conditions. Biotechnol. 9: 9-16 (2010).

[3] Pons, M.N., Rajab, A. and Engasser, J.M., Influence of acetate on growth kinetics and production control of Saccharomyces cerevisiae on glucose and ethanol. J. Appl. Micro. Biothec. 24: 193-198 (1986).

[4] Osho, A., Isolation, identification and screening of the yeast flora from indian cashew apple for sugar and ethanol tolerance. Int. J. Biotechnol. Wel. Indust. 6:259-265.(2005).

[5] Kreger-Van Rij.N.J.W., The Yeast a Taxonomic Study. New York, Elsevier Science Publishing Company,1984, pp. 1082.

[6] Kurtzman, C.P. and Fell, J.W., The Yeasts: A Taxonomic Study. 4th ed. , 1997.

[7] Apiradee S., Isolation and characterization of thermotolerant yeast for ethanol production a thesis submitted in partial fulfillment of the requirements for the degree of Master of Science in biotechnology, Suranaree University of technology (2006)

[8] Demirbas, A., Hazardous emissions, global climate change and environmental precautions. Eng. Sources 1: 75-84(2006).

[9] Warren, P. and shadomy, L., Yeast fermentation broth base with carbohydrate and Durham tube. Manual of Clinical Microbiology.5th ed. Washington D.C, 1991,.pp, 34-39.

[10] Sree, N. K., Sridhar, M., Rao, L.V., and Pandey, A., Ethanol production in solid substrate fermentation using thermotolerant yeast. Process Biochem. 34: 115-119. (1999).

[11] Fakruddin, Md., Ariful Islam, Abdul Quayum, Monzur Morshed Ahmed and Nayuum Chowdhury). Characterization of Stress tolerant High Potential Ethanol Producing Yeast from Agro-Industrial Waste. American Journal of BioScience 1: 24-34 (2013).

[12] Gimeno, C.J, Ljungdahl, P.O., Styles, C.A. and Fink, G.R., Unipolar cell divisions in the yeast S. cerevisiae lead to filamentous growth: regulation by starvation and RAS. Cell 68: 1077-1090 (2013).

[13] Sathees Kumar, R., Shankar, T. and Anandapandian K. T. KCharacterization of alcohol resistant yeast Saccharomyces cerevisiae isolated from Toddy. Int.l Res.J. Microbiolo. 26 : 399405.(2011).

\section{AUTHOR's BIOGRAPHY}

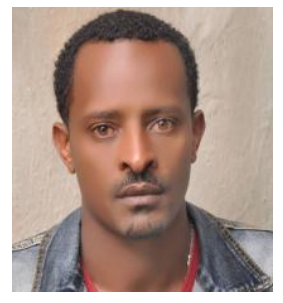

My Name is Taye Negera and I was born in Ethiopia. I am graduate of Addis Ababa University in applied biologyand Microbiology with B.Sc and M.Sc respective. As to my work experience, I have worked as junior researcher I at Oromia Agricultural Research institute, Bako Agricultural research center from January 01, 2009 to March 30, 2010. Joining Holeta Bee Research center by April 2010 as Associate researcher of Bee Health Research under Apicultural Research Case Team, I had been working on some research activities coordinating and implementing the sectors activity under its' objectives. In the team I was running different research activities which of some are completed and some are ongoing and other new activities. 